\title{
Unjuk Kerja Generator Clok Sinyal Low Pass Filter, Pam Multiplexing Pada Rangkaian Percobaan Pulse Code Mudulation (PCM) Aplikasi pada Laboratorium Dasar Sistem Telekomunikasi
}

\author{
Muhammad Adam, Partaonan Harahap \\ Program Studi Teknik Elektro, Fakultas Teknik \\ Universitas Muhammadiyah Sumatera Utara (UMSU) \\ J1. Kapten Muchtar Basri,BA No. 03 Medan Telp. (061) 6622400 ex. 12 Kode pos 20238 \\ e-mail: muhammadadam@umsu.ac.id
}

\begin{abstract}
Abstrak - Salah satu dari teknologi dasar sistem telekomunikasi digital adalah teknik modulasi digital, dimana teknik modulasi digital ini mengizinkan data digital untuk dibawa atau dipancarkan melalui saluran analog frekuensi radio. PCM berfungsi untuk mengubah sinyal analog menjadi digital. Dimana dalam sistem digital, sinyal analog yang dikirimkan cukup dengan sampel - sampelnya saja. Tahap awal dari proses perubah analog ke digital adalah PAM, yang merupakan saklar elektronik yang dikontrol oleh pulsa train (pulsa sampling). Namun, PAM adalah dasar dari metode pengkodean analog-ke-digital. yang penting yang disebut modulasi kode pulsa (PCM). Maka frekuensi dari hasil pengujian tegangan pada osiloskop sebesar 40 Volt dan PCM sebesar 25 volt dengan masing-masing frekuesi sebesar $50 \mathrm{~Hz}$ dan PCM sebesar $8 \mathrm{~Hz}$.
\end{abstract}

Kata kunci : Generator, pulsa PCM dan sinyal PAM Multiplexing

Abstract - One of the basic technologies of digital telecommunications systems is digital modulation techniques, where digital modulation techniques allow digital data to be carried or transmitted through radio frequency analog channels. PCM functions to convert analog signals into digital. Where in a digital system, the analog signal that is sent is enough with just the samples. The initial stage of the analog to digital conversion process is PAM, which is an electronic switch that is controlled by train pulses (pulse sampling). However, PAM is the basis of the analog-to-digital coding method. what's important is called pulse code modulation (PCM). Then the frequency of the test results on the oscilloscope voltage of 40 Volts and PCM of 25 volts with each frequency of $50 \mathrm{~Hz}$ and PCM of $8 \mathrm{~Hz}$.

Keywords : Generator, PCM pulses and PAM multiplexing signals

\section{PENDAhUlUaN}

Perkembangan teknologi dalam bidang telekomunikasi mengalami kemajuan yang sangat pesat. Ini terlihat dari indikasi berkembangnya industri telekomunikasi dan banyaknya aplikasi di bidang telekomunikasi yang digunakan dalam kehidupan sehari-hari. Pada sistem telekomunikasi, awalnya banyak teknologi yang menggunakan sistem telekomunikasi analog dan sekarang secara bertahap beralih menjadi sistem telekomunikasi digital. Salah satu dari teknologi dasar sistem telekomunikasi digital adalah teknik modulasi digital, dimana teknik modulasi digital ini mengizinkan data digital untuk dibawa atau dipancarkan melalui saluran analog frekuensi radio. Modulasi digital dapat dilakukan dengan memodulasi amplitudo, fasa, atau frekuensi, dan lebih dikenal dengan Amplitude Shift Keying (ASK), Phase Shift Keying (PSK), dan Frequency Shift Keying (FSK).

Sistem telekomunikasi dewasa ini dituntut terbebas dari gangguan sistem transmisi, seperti gangguan petir, gangguan saluran terlalu panjang, gangguan loncatan api dari pengapian motor dsb. Di samping itu juga dituntut kualitas reproduksi informasi yang bersih dan noise rendah. Untuk itu diperlukan sistem komunikasi digital yang prinsipnya merubah besaran analog ke dalam besaran digital, yang kemudian dipancarkan berupa pulsapulsa digital. Karena sistem digital hanya mempunyai kondiai logik "1" dan "0", maka level tegangan tidak ada artinya Pulse Code Modulation merupakan salah satu pengembangan sistem komunikasi digital untuk mengantisipasi gangguan oleh noise pada sinyal informasi, yang diakibatkan oleh saluran maupun media pengiriman sinyal melalui gelombang elektromagnetik. Pada rancangan ini dibanhgun sistem Pulse Code Modulator yang mengirimkan dua buah sinyal input yang berbeda secara bersamaan melalui proses multiplexing dan pulse amplitudo modulation. Hasilnya adalah pulsa-pulsa yang dikodekan ke dalam biner serial. Untuk mensinkronkan antara pengirim dan penerima dikirim pulsa sinkronisasi.

Modulasi dapat didefinisikan sebagai proses penyesuaian sinyal informasi yangakan dikirimkan 
agar sesuai dengan karakteristik saluran transmisi tertentu dengan memperhatikan tujuan dan efisiensi pengiriman sinyal tersebut. Efisiensi yang dimaksud mencakup dimensi fisik, absorbsi daya, pemakaian bidang frekuensi, ketahanan terhadap gangguan dari luar. Umumnya modulasi melibatkan penerjemahan baseband sinyal pesan yang dilewatkan dalam bandpass sinyal yang memiliki frekuensi jauh lebih tinggi dari sinyal informasi. Bandpass sinyal tersebut yang disebut dengan sinyal termodulasi dan baseband sinyal yang disebut dengan sinyal pemodulasi. Modulasi dapat dilakukan dengan memodulasi amplitude, fase, atau frekuensi.

PAM merupakan hasil pengolahan sinyal multipleksing yang mengandung informasi sinyal segi tiga dan sinyal kotak. Sinyal PAM tersebut memiliki masing-masing pulsa yang tinggi dan rendahnya level tergantung dari sinyal aslinya. Level amplitudo dari sinyal PAM tersebut, masing-masing akan diterjemahkan atau dikodekan menjadi dinyal digital melalui rangkaian analog to digital converter (ADC). Pulsa digital ini nantinya akan dikirim melalui sebuah media yang berupa penghantar kabel, ataupun dimodulasikan dengan sinyal pembawa yang biasanya menggunakan sistem Frequency Shift Keying (FSK) atau sistem modulasi yang lain.

Keunggulan lainnya adalah amplitude sinyal modulasi ini konstan sehingga bentuk selubung dari spectral sinyal ini akan tetap. Namun, filter premodulasi Gaussian dapat menimbulkan ISI (Intersymbol Interference) pada sinyal yang ditransmisikan. Sebagai akibat dari peningkatan efisiensi bandwidth akan ada degradasi dalam efisiensi daya.

\section{TINJAUAN PUSTAKA}

Herry Sudjendro (2014) melakukan penelitian 'Rancang Bangun Pulse Code Modulation (PCM)'.Pulse Code Modulation merupakan salah satu pengembangan sistemkomunikasi digital untuk mengantisipasi gangguan oleh noise pada sinyal informasi, yang diakibatkan oleh saluran maupun media pengiriman sinyal melalui gelombang elektromagnetik. Pada rancangan ini dibanhgun sistem Pulse Code Modulator yang mengirimkan dua buah sinyal input yang berbeda secara bersamaan melalui proses multiplexing dan pulse amplitudo modulation. Hasilnya adalah pulsa-pulsa yang dikodekan ke dalam biner serial. Untuk mensinkronkan antara pengirim dan penerima dikirim pulsa sinkronisasi.

Imam mahmuzi (2010) melakukan penelitian 'Analisa Dan Simulasi Berbagai Macam Teknik Modulasi Amplitude Shift Keying (ASK) Pada Kanal Berderau'. ASK (Amplitudo shift keying) merupakan metode pemodulasian berbasis amplitudo yangmerepresentasikan kode bit sebagai gelombang amplitudo tertentu. Metode yang dilakukan yaitu dengan menjaga suatu gelombang agar berada pada frekuensi yang konstan, tetapi memiliki amplitudo yang bervariasi guna mewakili data yang akan dikirimkan. Amplitudo tersebut harus terjaga minimal sampai dengan satu siklus gelombang terpenuhi, sehingga dapat diterjemahkan dengan benar oleh penerima. Dalam penelitian ini dirancang tiga jenis teknik modulasi yaituB-ASK, 4-ASK dan 8-ASK menggunakan program Matlab 7.8.0. Ketiga jenis teknik modulasi ini akan dioperasikan pada kanal berderau dan dirancang sesuai dengan teori ASK.

Herry Sudjendro (2014) melakukan penelitian 'Delta Modulasi Sebagai Solusi Mengatasi Gangguan Transmisi Sinyal'.Delta modulasi dirancang untuk mengatasi gangguan pada sistemkomunikasi analog dengan menerapkan sistem komunikasi digital 1 bit yang merupakan model paling sederhana. Level informasi sinyal analog akan dikodefikasi menjadi kedudukan sederetan bit yang merupakan hasil perubahan level analog ke pulsa digital. Pada reproduksi, sederetan pulsa delta modulasi akan diterjemahkan oleh rangkaian integrator sebagai informasi naik atau menurun, sehingga dihasilkan sinyal informasi sesuai sumbernya.

\section{Teori Modulasi}

Modulasi merupakan proses pengubahan informasi menjadi bentuk yang sesuai dengan media transmisi. Bila sinyal dimodulasi, maka ia akan dapat menempuh jarak yang jauh serta dapat sesuai dengan media transmisi yang dilaluinya. Sedangkan proses kebalikannya disebut demodulasi, yaitu perubahan

bentuk data yang dikirim menjadi bentuk data yang dapat ditangkap dan digunakan oleh penerimanya(Wahyono, Teguh, 2003). ASK (Amplitude Shift Keying) adalah suatu modulasi dimana logika 1 diwakili dengan adanya sinyal dan logika 0 diwakili dengan adanya kondisi tanpa sinyal, seperti pada gambar berikut ini:
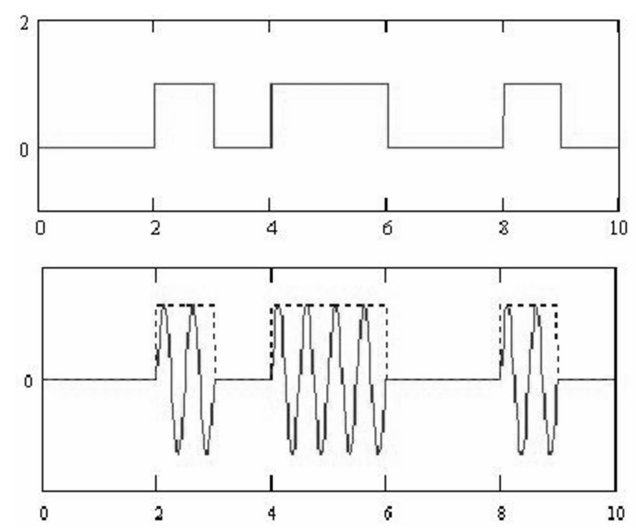

Gambar 1. Amplitude Shift Keying (ASK) 
Hasil ASK (Amplitude Shift Keying) diwakili oleh perbedaan amplitudo pada carrier. Di mana satu amplitudo adalah zero, ini menunjukkan kehadiran dan ketidak hadiran pada carrier yang digunakan. PCM / Pulse Code Modulation atau Modulasi Kode Pulsa adalah salah satu teknik memproses suatu sinyal analog menjadi sinyal digital melalui kodekode pulsa. Proses-proses utama pada sistem PCM, diantaranya Proses Sampling (Pencuplikan), Quantizing (Kuantisasi), Coding (Pengkodean), Decoding (Pengkodean Kembali).

1. Sampling adalah : proses pengambilan sample atau contoh besaran sinyal analog pada titik tertentu secara teratur dan berurutan Frekuensi sampling harus lebih besar dari $2 \mathrm{x}$ frekuensi yang disampling (sekurang-kurangnya memperoleh puncak dan lembah) Hasil penyamplingan berupa PAM (Pulse Amplitude Modulation

2. Quantisasi : Proses menentukan segmensegmen dari amplitudo sampling dalam level-level kuantisasi Amplitudo dari masing-masing sample dinyatakan dengan harga integer dari level kuantisasi yang terdekat

3. Pengkodean : proses mengubah (mengkodekan) besaran amplitudo sampling ke bentuk kode digital biner

4. Multiplexing : dari banyak input menjadi satu output fungsi : Untuk penghematan transmisi Menjadi dasar penyambungan digital

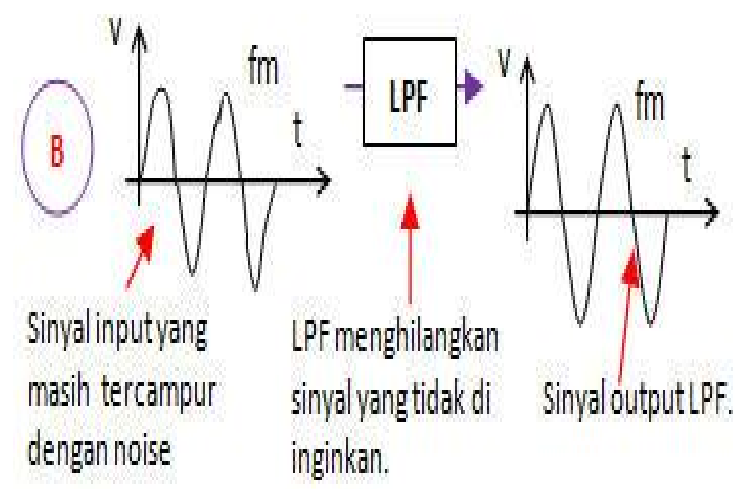

Gambar 2. $\mathrm{LPF}=$ Low Pass Filter $\mathrm{A} / \mathrm{D}=$ Analog to Digital $\mathrm{P} / \mathrm{S}=$ Paralel to Serial

Pada Gambar A ditunjukkan diagram blok proses pengiriman pada PCM diantaranya: Filter (LPF), Sampler, Quantizer dan Coder. Pada tahap pertama, sinyal input (analog) dengan frekuensi fm masih bercampur dengan noise atau sinyal lain yang berfrekuensi lebih tinggi. Untuk menghilangkan sinyal-sinyal yang tidak di inginkan(noise) tersebut digunakan LPF (low pass filter) seperti yang ditunjukkan Gambar B.

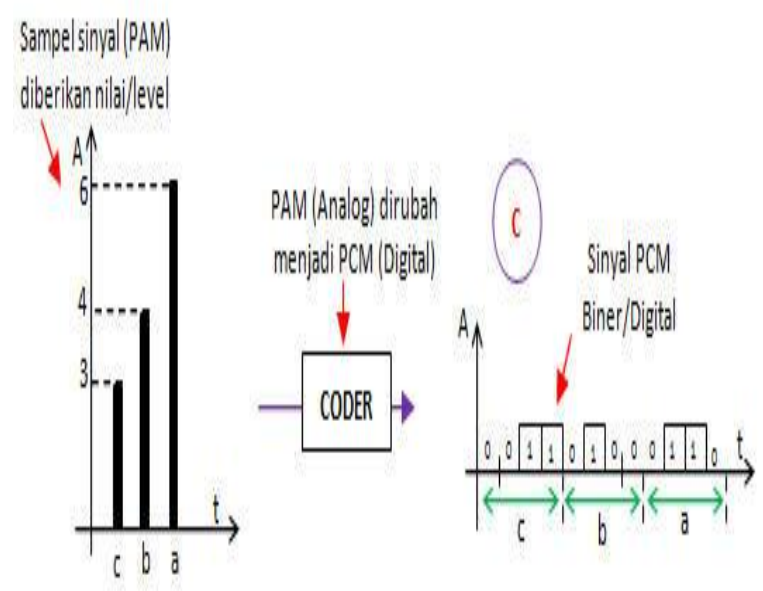

Gambar 3. fm $=$ frekuensi informasi $\mathrm{t}=$ time $/$ waktu $\mathrm{v}=$ amplitudo $/$ tegangan

Setelah sinyal di filter, selanjutnya adalah pengambilan sample seperti yang ditunjukkan pada Gambar A dan C. Frekuensi sampling (fs) harus lebih besar atau sama dengan dua kali frekuensi sinyal informasi ( $\mathrm{fs}=2 \mathrm{fm})$; sesuai dengan Theorema Nyquist. Sinyal output sampler disebut sinyal PAM (Pulse Amplitudo Modulation).

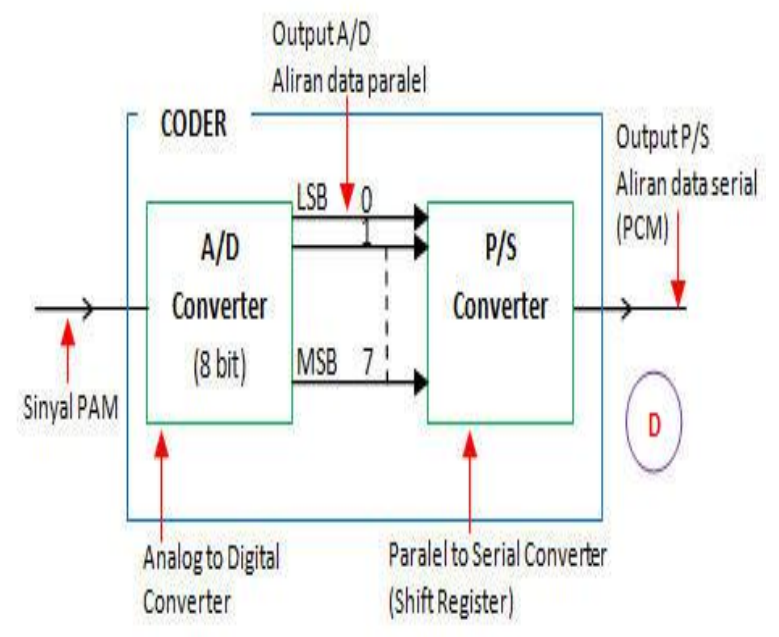

Gambar 4. sinyal PAM (Pulse Amplitudo Modulation).

Sinyal PAM tersebut yang merupakan potongan dari sinyal aslinya kemudian diberi nilai (level) sesuai dengan amplitudo dari masing-masing sample sinyal (Gambar C). Jumlah pembagian level sinyal yang digunakan disuaikan dengan jumlah bit yang di inginkan untuk mengkodekan satu sample sinyal PAM berdasarkan persamaan berikut: 


$$
N=2^{\mathrm{n}}
$$

$N$ adalah jumlah level sample yang di ambil dan $n$ adalah jumlah bit yang digunakan untuk mengkodekan satu sinyal PAM. Misalkan sinyalsinyal PAM tersebut akan dikodekan menjadi 4 bit maka jumlah level yang akan diperoleh adalah:

$$
N=2^{4}=16
$$

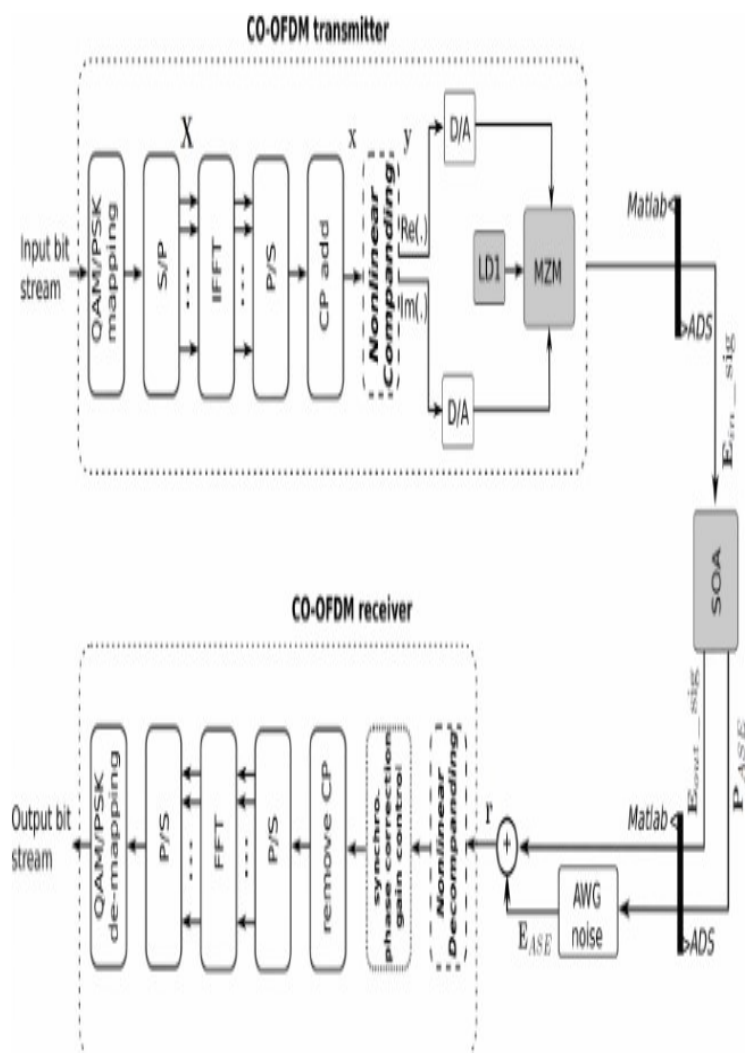

\section{Gambar 5. LSB = Low Significant Band MSB = Most Significant Band}

Selanjutya, setiap sample yang telah terkuantisasi masuk ke dalam blok CODER. Pada tahapan ini , sample sinyal yang masih berbentuk analog dirubah menjadi biner dengan urutan serial. CODER sendiri terdiri dari dua blok utama yaitu, A/D Converter yang berfungsi untuk merubah sinyal analog menjadi biner, akan tetapi keluarannya masih dalam bentuk parallel seperti yang di tunjukkan Gambar D, karenanya di butuhkan blok kedua berupa $\mathrm{P} / \mathrm{S}$ Converter agar deretan biner menjadi serial.
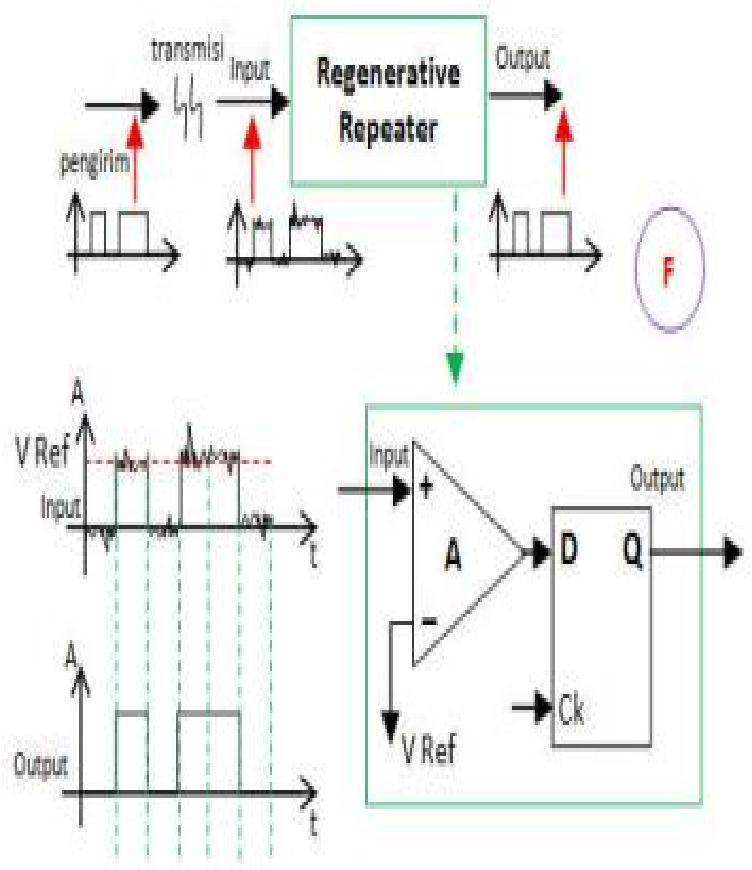

Gambar 6. $\mathrm{S} / \mathrm{P}=$ Serial to Parallel $\mathrm{D} / \mathrm{A}=$ Digital to Analog

Pada penerima (Gambar E) sinyal yang masuk telah mengalami peredeman dan kembali bercampur dengan berbagai sinyal lain yang tidak di inginkan (noise) selama proses pengiriman, hal ini merusak sinyal informasi sehingga akan lebih sulit untuk di proses. Karenanya, sinyal harus diperbaiki terlebih dahulu dengan menggunakan "Regenerative Repeater" seperti yang ditunjukkan pada Gambar E dan F.

Osilator dengan penguat, induktor dan kapasitor pada dasarnya merupakan osilator yang memanfaatkan rangkaian resonansi seri induktor dan kapasitor (LC). Secara teoritis, induktor dan kapasitor akan mengalami resonansi. Akan tetapi adanya redaman akibat resistansi pada induktor dan konduktansi pada kapasitor osilasi tersebut tidak dapat terjadi dengan sendirinya. Untuk menjamin terjadinya osilasi tersebut, maka rangkaian LC harus mendapat mekanisme kompensasi terhadap redaman. Pada implementasinya maka induktor dan kapasitor ditempatkan dalam rangkaian umpan balik guna menjaga resonansi berkelanjutan.

Prinsip rangkaian penguat dan umpan balik untuk ketiganya tampak pada gambar. Frekuensi osilasi rangkaian ini ditentukan oleh rangkaian resonansinya. 


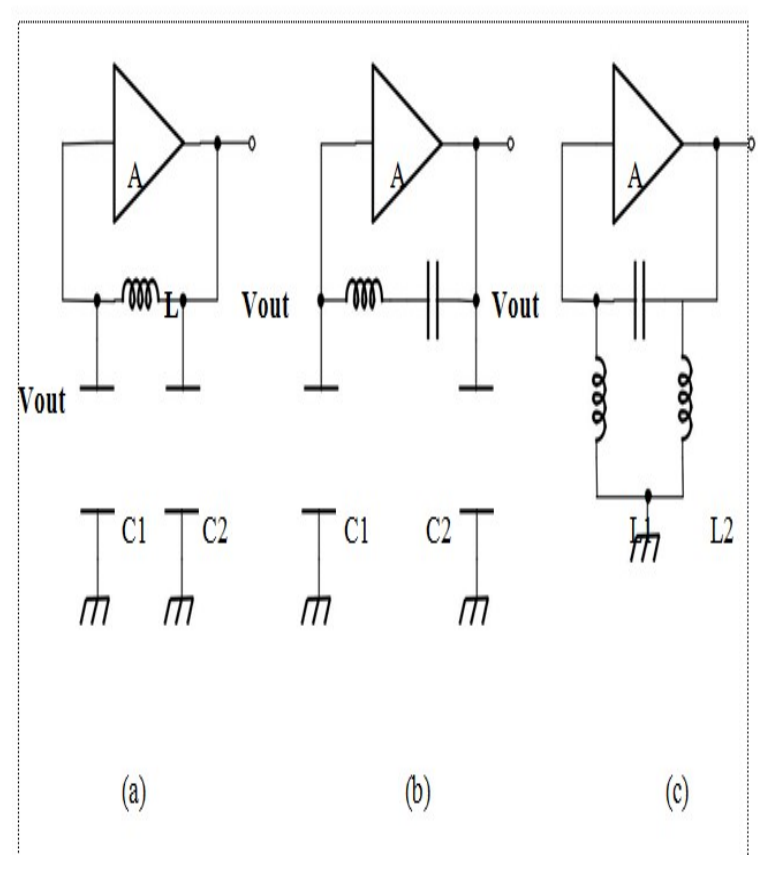

Gambar 7. Osilator LC (a) Colpitts (b) Clapp, dan (c) Hartley

\section{Mixer}

Sebuah mixer, sesuai dengan namanya, merupakan rangkaian yang akan mengolah dua buah input signal dan kemudian menggabungkannya sebagai sebuah output signal. Secara umum terdapat dua jenis mixer, yakni linear dan non linear. Sebuah mixer linear, merupakan rangkaian yang menjumlahkan dua buah signal input.

\section{Phase Detector}

Sebuah rangkaian phase detector, akan menghasilkan signal output yang sebanding dengan selisih phase dari dua buah signal yang memiliki frekuensi yang sama. Untuk selisih phase antara dua buah signal dengan frekuensi yang sama disebut dengan istilah phase shift. Sebuah phase detector akan menghasilkan serangkaian pulsa output yang mana lebarnya sebanding dengan selisih phase kedua signal tersebut. Dengan melewatkan pulsa tersebut pada rangkaian Low Pass Filter, akan menghasilkan output rata-rata tegangan DC yang lebih halus.

\section{Phase Locked Loop}

Phase Locked Loop atau sering juga disebut dengan PLL, merupakan suatu rangkaian kendali feedback yang peka terhadap frekuensi dan phase signal gelombang tersebut. Phase Locked Loop terdiri dari tiga komponen utama, yakni mixer atau phase detector, Low Pass Filter, dan juga Voltage Controlled Oscillator. Untuk signal dari VCO, akan dibandingkan dengan dengan input signal. Jika terdapat selisih frekuensi atau phase antara kedua signal, akan dihasilkan signal error. Untuk signal error tersebut, akan ditapis terlebih dahulu dengan Low Pas Filter, menjadi output DC. Untuk selanjutnya output DC tersebut akan menjadi feedback signal untuk VCO.

\section{Frequency Synthesizer}

Salah satu penggunaan dari PLL, ialah frequency synthesizer. Sebuah frequency synthesizer, merupakan sumber signal yang stabil dan dapat diatur jangkauan frekuensi yang diinginkan. Frequency synthesizer biasa digunakan untuk menghasilkan signal secara tepat dan stabil, baik untuk tujuan pengujian maupun pengukuran. Salah satu kelebihan dari frequency synthesizer, yakni kemampuannya untuk menghasilkan frekuensi daengan jangkauan yang luas, tingkat ketepatan yang relatif baik, serta stabil, melalui sebuah sumber penghasil signal.

\section{METODE}

Observasi yang telah dilakukan pada Pulse Code Modulation yang merupakan salah satu pengembangan sistem komunikasi digital untuk mengantisipasi gangguan oleh noise pada sinyal informasi, yang diakibatkan oleh saluran maupun media pengiriman sinyal melalui gelombang elektromagnetik. Pada rancangan ini dibanhgun sistem Pulse Code Modulator yang mengirimkan dua buah sinyal input yang berbeda secara bersamaan melalui proses multiplexing dan pulse amplitudo modulation. Hasilnya adalah pulsa-pulsa yang dikodekan ke dalam biner serial. Untuk mensinkronkan antara pengirim dan penerima dikirim pulsa sinkronisasi.

\section{Tempat dan lokasi penelitian}

Kegiatan penelitian ini bertempat di laboratorium Fakultas Teknik Prodi Teknik Elektro UMSU.

\section{Langkah -langkah pengukuran :}

1. Mengukur gelombang pada test poin Clok

2. Mengukur tegangan peak to peak pada Rangkaian PCM 2 kanal

3. Mengukur teganagan peak to peak pada input dan output LPF

4. Mengukur sinyal output pada PAM Multiplexing dan sinyal Sinkron.

5. Mengukur sinyal clok 16 dengan Frekuensi counter yaitu :
a. Frekuensi clok
$=135 \mathrm{kHz}$
b. Frekuensi clok 16 


\section{HASIL DAN PEMBAHASAN}

PCM berfungsi untuk mengubah sinyal analog menjadi digital. Dimana dalam sistem digital, sinyal analog yang dikirimkan cukup dengan sampel sampelnya saja. Tahap awal dari proses perubah analog ke digital adalah PAM, yang merupakan saklar elektronik yang dikontrol oleh pulsa train (pulsa sampling) selebar $1 /$ fs. Sinyal yang dihasilkan adalah sinyal chopp dengan lebar pulsa $=$ To . Proses ini dinamakan time discretization

1. Hasil pengujian tengangan output rangkaian filter dengan AF Generator

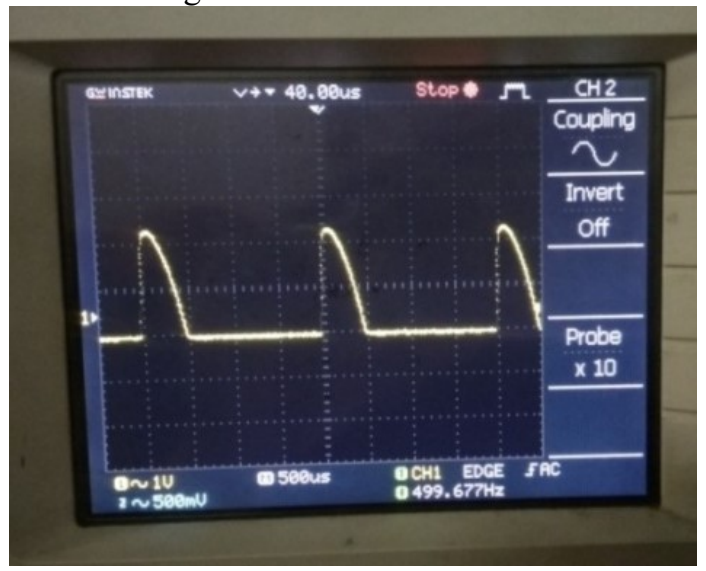

Gambar 8. Output gelombang Generator

2. Hasil pengujian pada rangkaian PCM (pulsa Code Modulasion)

Pembagi dua rangkaian berfungsi untuk membagi dua frekuensi dari suatu gelombang kotak dari rangkaian PCM (pulsa Code Modulasion)

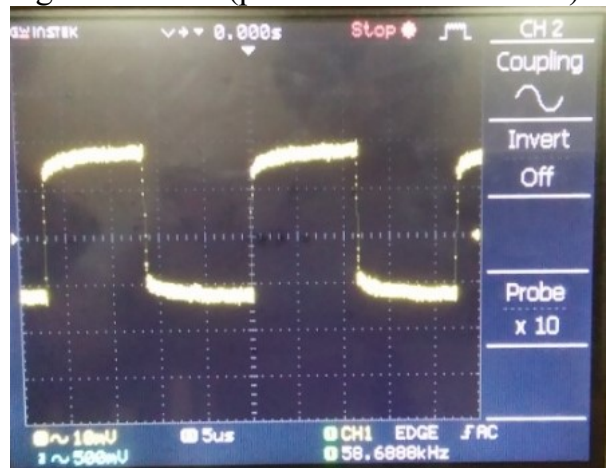

Gambar 9.Hasil Pengujian PCM (pulsa Code Modulasion)

3. Hasil pengujian Generator, sinyal PAM Multiplexing,dan pulsa PCM.

Pulse Code Modulation suatu teknik konversi sinyal analog-todigital dan digital-to-analog yang digunakan untuk transmisi sinyal informasi seperti suara, gambar dan video. Pulse Code Modulation (PCM) adalah pengembangan dari PAM (Pulse Amplitude Modulation) dimana tiap-tiap sampel analog dikuantisasi dan disajikan dalam bentuk kodekode digital. Prinsip kerja pulse code modulation ada
3 proses utama yaitu sampling, quantizing, dan coding. Untuk mendapatkan sinyal PCM output dengan menggunakan oscilloscope pada clock generator posisi switch pada keadaan fast. Hasil dari PCM output berupa gelombang kotak seperti pulsa.

Tabel 1. Generator, sinyal PAM Multiplexing,dan pulsa PCM

\begin{tabular}{|l|c|c|c|c|}
\hline \multicolumn{1}{|c|}{$\begin{array}{c}\text { Parameter } \\
\text { pengujian }\end{array}$} & $\begin{array}{c}\text { Tegangan } \\
\text { Osiloscope } \\
\text { (Volt) }\end{array}$ & $\begin{array}{c}\text { Time } \\
\text { Osiloscope } \\
\text { (S) }\end{array}$ & $\begin{array}{c}\text { Frekuensi } \\
\text { Osiloscope } \\
\text { (Hz) }\end{array}$ & $\begin{array}{c}\text { Vrms } \\
\text { (Volt) }\end{array}$ \\
\hline Generator & 2 & 1 & 1 & 2,8 \\
\hline LPF 3,45 KHz & 50 & 0,125 & 8 & 0,8 \\
\hline PAM Multiplexing & 40 & 0,02 & 50 & 4,2 \\
\hline $\begin{array}{l}\text { PCM (pulsa Code } \\
\text { Modulasion) }\end{array}$ & 25 & 0,125 & 8 & 1,07 \\
\hline
\end{tabular}

Pada rangkaian Pulse Code Modulation terdiri dari clock generator, voltage follower, voltage comparator, counter, latch dan shift register. Pertama memberikan sinyal masukan berupa analog input misalnya gelombang sinusoidal pada voltage follower. Output voltage follower tersebut lalu di input pada voltage comparator. Rangkaian voltage follower berada sebelum voltage comparator yang berfungsi agar sinyal yang keluar dari voltage follower sama dengan sinyal masukannya.

\section{KESIMPULAN}

Pulsa Code Modulsion (PCM) juga disebut sebagai metode pengambilan sampel yang digunakan dalam PAM lebih berguna untuk bidang teknik lain daripada komunikasi data. Namun, PAM adalah dasar dari metode pengkodean analog-ke-digital. yang penting yang disebut modulasi kode pulsa (PCM). Maka frekuensi dari hasil pengujian tegangan pada osiloskop sebesar 40 Volt dan PCM sebesar 25 volt dengan masing-masing frekuesi sebesar $50 \mathrm{~Hz}$ dan PCM sebesar $8 \mathrm{~Hz}$.

\section{DAFTAR PUSTAKA}

[1] Alaydrus, M. (2011). Antena; Prinsip \& Aplikasi. Yogyakarta: GRAHA ILMU.

[2] Balanis Constantine, A. (2005). Antenna Theory Analysis and Design. WILEY.

[3] Basuki, Hari Satriyo. (1998). Macam-Macam Sistem Antena Radio Siaran FM. Bulletin IPT, Vol. 1 hal. 2.

[4] Bastian Damanik, Andreas.(2011). Perencanaan Spektrum Digital Dividend Pada Pita

[5] Barry Davis, (1981) Under standing DC Power Suppllies, Prentice-Hall of Australia Pty Ltd,

[6] Dian Putri Maulina (2015) Politeknik Negeri Sriwijaya Palembang dengan hasil penelitiannya, Osilator merupakan rangkaian yang dapat 
menghasilkan sinyal output tanpa adanya sebuah sinyal input yang diberikan

[7] Edy Burnawi,(1996) Catu Daya , PPPGTeknologi Bandung

[8] Emst Hornermann, (1988), Electrical Power Engineering Profinciecy Course, GTZ GmbHEscbom ( Federal Republic of Germany)

[9] Fardo and Patrick, Electrical Power Systems Technology, Howard W.Sams \& Co,Inc

[10] Gunawan, (2012) "Antena WIFi, Perancangan Antena Portable”, Volume 1. NO. 5, Universitas Muhammadiyah Riau, Pekanbaru
[11] Harpawi, noptin. (2013). Design Energy Harvesting Device of UHF TV Stations. Bandung: InstitutTeknologi Bandung

[12] Iga Ayu (2015) Perencanaan collpis Osilator Frekuensi $1 \mathrm{MHz}$ Dengan Resistansi Negatif Pada Peralatan NDB Tipe 200

[13] Toni, S.I.P, M.Si,David Octa Rengga (2017) Sekolah Tinggi Penerbangan Indonesia Curug, Tangerang. Dengan judul Rancangan Osilator Menggunakan Metode Phase Lock Loop Untuk Peralatan Transceiver Vhf Air To Ground Tower Set Di Program Studi Teknik Telekomunikasi Dan Navigasi Udara $\$ 